\title{
The antitumor activity screening of chemical constituents from Camellia nitidissima Chi
}

\author{
XIAOYING HOU ${ }^{1 *}$, HONGZHI DU $^{1 *}$, RUI YANG $^{2}$, JING $^{2}{ }^{2}$, YUE HUANG $^{1}$, SHUYUN FENG $^{1}$, YAO WU $^{1}$, \\ SENSEN LIN ${ }^{3}$, ZHIXIN LIU ${ }^{4}$, AI-QUN JIA ${ }^{2}$, SHENGTAO YUAN ${ }^{3}$ and LI SUN ${ }^{1}$ \\ ${ }^{1}$ Jiangsu Key Laboratory of Drug Screening, China Pharmaceutical University, Nanjing, Jiangsu 210009; \\ ${ }^{2}$ School of Environmental and Biological Engineering, Nanjing University of Science and Technology, \\ Nanjing, Jiangsu 210094; ${ }^{3}$ Jiangsu Center for Pharmacodynamics Research and Evaluation, China Pharmaceutical University, \\ Nanjing, Jiangsu 210009; ${ }^{4}$ Guangxi Gui RenTang Co., Ltd., Fangchenggang 538021, P.R. China
}

Received December 15, 2016; Accepted February 7, 2018

DOI: $10.3892 /$ ijmm.2018.3502

\begin{abstract}
Chemotherapy is the preferred and most common treatment for cancer in clinical practice. An increasing number of researchers all over the world are focusing on natural medicines to find new antitumor drugs, and several reports have shown that Camellia nitidissima ( $C$. nitidissima) Chi could reduce blood-lipid, decrease blood pressure, resist oxidation, prevent carcinogenesis and inhibit tumors. Therefore, the pharmacodynamics of the chemical constituents in $C$. nitidissima need to be investigated further. In the present study, 16 chemical constituents were isolated from the leaves of $C$. nitidissima, of which 6 compounds are reported to be found in this plant for the first time. Furthermore, all these phytochemicals were screened for antitumor activity on 4 common cancer cell lines, while compound 3, one oleananetype triterpene, exhibited the most potential antitumor effects. Interestingly, to our knowledge, this was the first report that compound 3 inhibits cancer cells. Compound 3 inhibited EGFR-mutant lung cancer cell line, NCI-H1975 via apoptosis effect, with an $\mathrm{IC}_{50}$ of $13.37 \pm 2.05 \mu \mathrm{M}$ at $48 \mathrm{~h}$. Based on the data, compound 3 showed potential for antitumor drug development, suggesting the scientific basis for the antitumor activity of $C$. nitidissima.
\end{abstract}

Correspondence to: Professor Shengtao Yuan, Jiangsu Center for Pharmacodynamics Research and Evaluation, China Pharmaceutical University, 24 Tongjiaxiang Street, Nanjing, Jiangsu 210009, P.R. China E-mail: cpuyuanst@163.com

Professor Li Sun, Jiangsu Key Laboratory of Drug Screening, China Pharmaceutical University, 24 Tongjiaxiang Street, Nanjing, Jiangsu 210009, P.R. China

E-mail:sunli@cpu.edu.cn

*Contributed equally

Key words: Camellia nitidissima Chi, chemical constituents, antitumor activity, apoptosis effect

\section{Introduction}

China is facing critical issues caused by cancer with nearly 2 million cancer deaths and more than 3 million cancer incidences annually (1). Currently, chemotherapy, surgery, radiotherapy, biotherapy and other adjuvant therapy are common treatments for tumor. However, chemotherapy is the preferred and the most common treatment for patients in clinical practice (2). Yet, it is still lacks effective antitumor drugs, while some patients easily acquire resistance to many new drugs after a period of treatment. For example, the mutation of T790M confers resistance to first-generation EGFR TKIs. Therefore, there is an urgent need to find new and effective antitumor drugs (3). Moreover, many chemotherapy drugs in clinical practice are from natural medicine, such as paclitaxel, vincristine, oxymatrine, and podophyllotoxin (4). An increasing number of researchers (5-7) from all over the world have been focusing on natural medicines to find new antitumor drugs.

Camellia nitidissima (C. nitidissima) Chi (Theaceae family) is an evergreen tree, grown mainly in Guangxi, China. It is a popular commercial and ornamental plant with goldenyellow flowers. $C$. nitidissima has also been classified as one of the rarest plants in China, and is known as 'flora panda' and 'camellia queen'. The tree contains saponins, flavonoids, polyphenols, vitamins, amino acids and other nutrients for the organism (8). Therefore, locally $C$. nitidissima plays an important role in human health. Moreover, several studies (8-10) showed that $C$. nitidissima could reduce blood-lipid, decrease blood pressure, resist oxidation, prevent carcinogenesis and inhibit tumor growth. However, most of the pharmacodynamics studies of $C$. nitidissima are based on the crude extracts from the camellia. Therefore, it is necessary to investigate bioactive phytochemicals in $C$. nitidissima.

In this study, 16 phytochemicals were isolated from the leaves of $C$. nitidissima by undergoing purification via repeated silica gel chromatography (Sephadex LH-20, MCI gel columns), recrystallization, and semi-preparative HPLC techniques. The chemical structures were identified on the basis of spectral data including NMR and MS. Subsequently, the antitumor activity screening of the chemical constituents on 4 common 
cancer cell lines were detected by 3-(4,5-dimethylthiazol-2-yl)2,5-diphenyltetrazolium bromide (MTT) assays. In further experiments, we evaluated the $\mathrm{IC}_{50}$ of compound 3 on the NCI-H1975 and detected the apoptosis effect by Annexin V/PI double staining to explore the potential mechanism. Finally, the apoptosis effect was confirmed by western blot analysis.

In brief, 16 chemical constituents were isolated from the leaves of $C$. nitidissima, and 6 phytochemicals (compound 2, $3,5,6,7$ and 10) were first reported in this plant in this study, while other 8 phytochemicals were first reported in this plant in our previous published study (11). Furthermore, we evaluated the antitumor activity of 16 phytochemicals on 4 different cancer cell lines ( 3 different cancer types). To our knowledge, it is the first study that compound 3 has the most potent antitumor effect, based on the screening data of 4 common malignant cancer cells, showing potential for antitumor drug development.

\section{Materials and methods}

Preparation of chemical constituents. The leaves from C. nitidissima were collected from Fangchenggang, China, and authenticated by Mr. Ji-zhu Yang (where?). The leaves were air-dried and coarsely powdered. The powdered leaves of C. nitidissima $(6.3 \mathrm{~kg})$ were extracted with $95 \%$ ethanol three times (3, 2 and $1 \mathrm{~h}$ ) under reflux. The ethanolic extracts were combined and concentrated under reduced pressure. The concentrated extract was suspended in water, partitioned with ethyl acetate (EtOAc, Shuangling Chemical Reagent Co. 295 g), and n-butanol (n-BuOH, Shuangling Chemical Reagent Co. $137 \mathrm{~g})$ successively. The EtOAc fraction $(285 \mathrm{~g})$ was subjected to silica gel column chromatography and eluted with a petroleum ether-acetone (PE-CP, 10:1 $\rightarrow 0: 1)$ gradient system to yield six fractions (Frs. 1-6) on the basis of TLC analysis. Fr. 1 was further subjected to silica gel column chromatography and eluted with PE-CP (5:1) to obtain the compounds; compound 1 , compound 2 , compound 3 , compound 15 , and compound 16 . Compound 5 , compound 6 , and compound 7 were obtained from Fr. 4. Seven subfractions from Fr. 1 were subjected to repeated silica gel chromatography, including C18 silica gel chromatography, Sephadex LH-20 chromatography, and MCI gel column chromatography, and a semi-preparative HPLC technique (Agilent HPLC with Hypersil ODS column (150x4.6 mm), respectively. compound 4 was obtained from sub-fraction 1; compound 8 and compound 12 were obtained from subfraction 3; and compound 13 , compound 4 , and compound 11 were obtained finally from sub-fraction 4; Compound 13 was obtained from Fr. 5; compound 14 was recrystallized from Fr. $6\left(\mathrm{CH}_{2} \mathrm{Cl}_{2}-\mathrm{MeOH}\right.$ 10:1). Compounds 9 and 10 were obtained by further silica gel column chromatography $\left(\mathrm{CH}_{2} \mathrm{Cl}_{2}-\mathrm{MeOH} 10: 1\right)$ of this fraction.

Cell culture. The human lung cancer cell lines, A549 and NCI-H1975 were cultured in RPMI-1640 (Gibco, Grand Island, NY, USA). The human gastric cancer cell line, HGC-27 was cultured in Dulbecco's modified Eagle's medium (DMEM; Gibco). The colon cancer cell line, SW620 was cultured in L-15 (Gibco). All the cell lines were obtained from the Cell Bank of the Institute of Biochemistry and Cell Biology,
Chinese Academy of Sciences (Shanghai, China). The media were supplemented with $10 \%$ fetal bovine serum (FBS; Gibco), $100 \mathrm{U} / \mathrm{ml}$ penicillin and $100 \mathrm{U} / \mathrm{ml}$ streptomycin. The cells were incubated in a humidified atmosphere with $95 \%$ air and $5 \% \mathrm{CO}_{2}$ at $37^{\circ} \mathrm{C}$.

Cell proliferation assays. Cell proliferation assays were performed by MTT as previously described. Briefly, cells were harvested, washed with phosphate-buffered saline (PBS) and digested with trypsin, then plated in 96-well plates, at a density of $\sim 2 \times 10^{3}$ cells in each well. Twelve hours later, cells were treated with chemical constituent at specified concentrations for additional $48 \mathrm{~h}$. Then cells were treated with MTT for $4 \mathrm{~h}$. After the media was removed, the newly formed formazan was dissolved and measured by enzyme-linked immunosorbent assay (ELISA) reader at a wavelength of $570 \mathrm{~nm}$, and the results are presented as mean standard deviation (SD). In addition, triplicate experiments were performed in parallel.

Annexin V/PI double staining. The apoptosis effect was detected by the Annexin V/PI double staining. After treatment with chemical constituents for $48 \mathrm{~h}$, the apoptotic cells were stained by the Annexin V-FITC Apoptosis Detection kit (Vazyme Biotech, Jiangsu, China). Then, the stained cells were immediately analysed by flow cytometry. Data acquisition and analysis were performed with a Becton-Dickinson FACSCalibur flow cytometer via the Cell Quest software (Becton-Dickinson, Franklin Lakes, NJ, USA).

Western blot analysis. Total cell lysates were extracted from the untreated and treated cells, adding phosphatase and protease inhibitors. The proteins were fractionated by 6-15\% sodium dodecyl sulfate-polyacrylamide gel electrophoresis (SDS-PAGE) and electroblotted onto PVDF membrane (Millipore, Billerica, MA, USA). Subsequently, the membranes were blocked with 5\% non-fat milk and incubated with primary antibodies (diluted in 1\% BSA-TBST) for $18 \mathrm{~h}$ at $4^{\circ} \mathrm{C}$. Next, they were probed with secondary antibodies for $1 \mathrm{~h}$ at room temperature. Subsequently, the expression of the target proteins was detected by Immobilon Western Chemiluminescent HRP Substrate (Millipore).

Statistical analysis. The results were expressed as the means \pm standard deviation (SD). GraphPad Prism 5.0 and Student's t-test were used to determine the level of significance. Only the P-value of $<0.05$ was considered as statistically significant.

\section{Results}

Sixteen chemical constituents were isolated and identified from the leaves of C. nitidissima. Based on a previous study (9), we explored the phytochemicals derived from the extractive fractions of $C$. nitidissima with antitumor effect, according to the flow diagram shown in Fig. 1. Finally, 16 compounds, including flavonoids, C-27 steroidal saponins, monoterpenes, and triterpenes were identified as follows: compound 1: $3 \beta$-acetoxy-20-

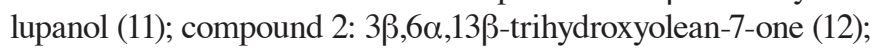
compound 3: A1-barrigenol-22a-angelate (13); compound 4: (3R, 6R, 7E) -3-hydroxy-4,7-megastigmadien-9-one (11); compound 5: $\beta$-D-glucopyranoside, 3-[(1-oxo-9,12,15-octadecadienyl)oxy]- 
A
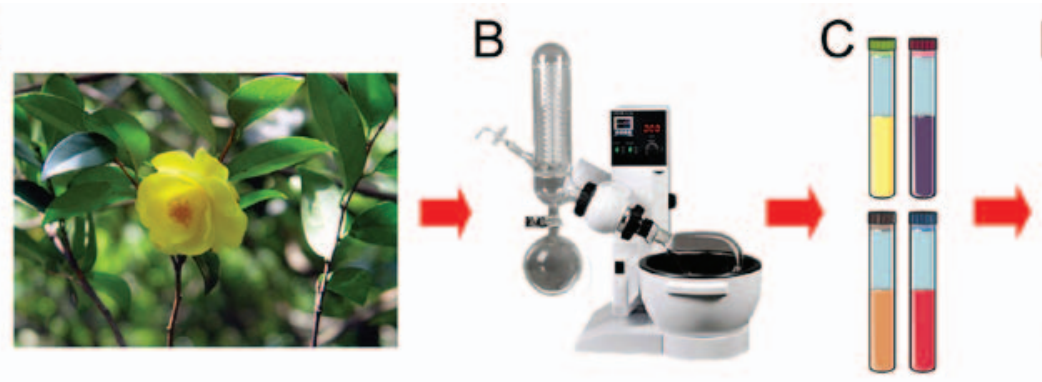

G
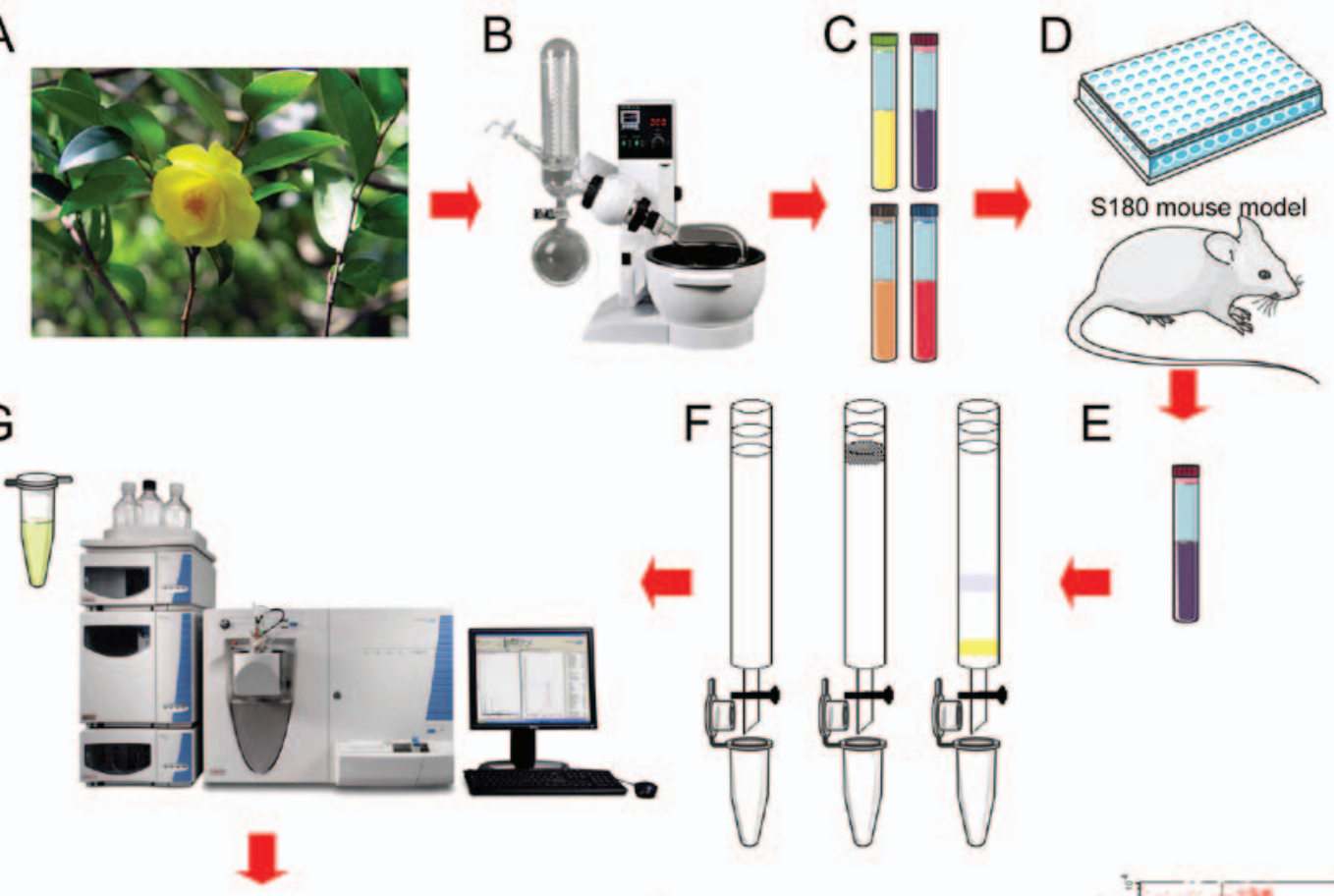

$\mathrm{E}$

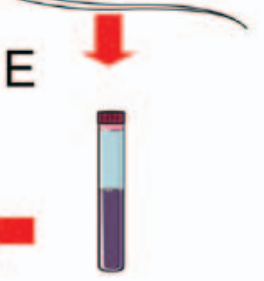

$\mathrm{H}$
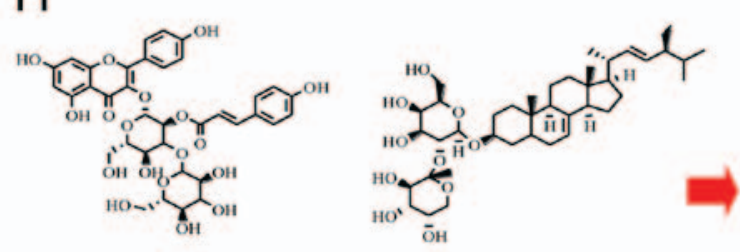

I
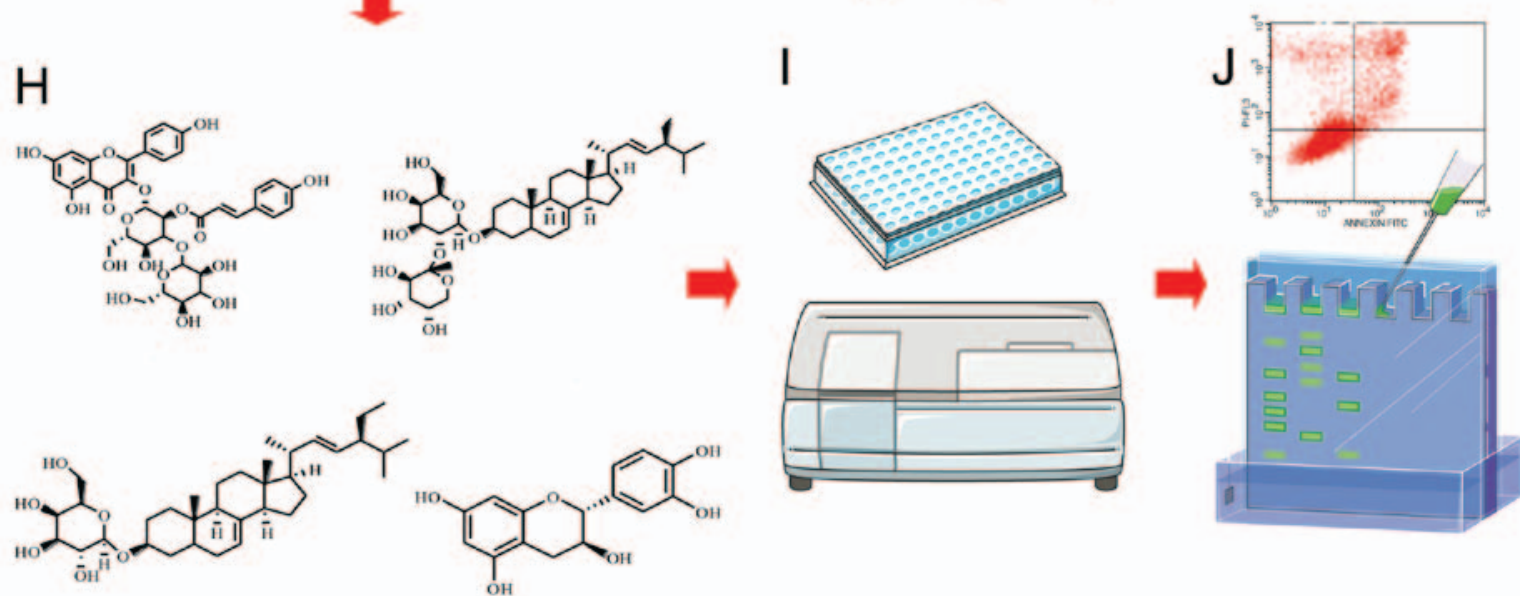

Figure 1. The antitumor activity screening of chemical constituents. (A) The plant of Camellia nitidissima Chi. (B) The process of extraction. (C) The different extractive fractions of Camellia nitidissima Chi. (D) The antitumor activity screening of different extractive fractions were analysed by MTT assays and mouse sarcoma 180 subcutaneous graft tumor model. (E) The effective extractive fraction. (F) The separation of effective fraction. (G) The identification of the chemical constituents. (H) Sixteen chemical constituents were derived from Camellia nitidissima Chi. (I) The antitumor activity screening of 16 chemical constituents. (J) The mechanisms were explored by apoptosis assay and western blot analysis.

2-[(1-oxo-9,12,15-octadecatrienyl)oxy (14); compound 6: $\beta$-D-glucopyranoside, 2-[[(9Z,12Z,15Z)-1-oxo-9,12,15octadecatrien-1-yl]oxy]-3-[(1-oxooctyl)oxy]propyl (15); compound 7: $\beta$-D-Glucopyranoside,3-[(1-oxo-9,12-octadecadienyl)oxy]-2-[(1-oxo-9,12,15-octadecatrienyl)oxy]propyl (16); compound 8: kaempferol3-O-[2-O-(trans-p-coumaroyl)-3-O- $\alpha$ D-glucopyranosyl]- $\alpha$-D-glucopyranoside (11); compound 9: stigmasta-7,22-diene-3-O-[ $\alpha$-L-arabinopyranosyl $(1 \rightarrow 2)]-\beta$-D-galactopyranoside (11); compound 10: $\beta$-D-galactopyranoside, (2S)-2-(acetyloxy)-3-[[(9Z)-1-oxo-9-octadecen-1-yl] oxy]propyl (17); compound 11: aromadendrin(11); compound 12: $\alpha$-spinasteryl- $\beta$ D-glucopyranoside (11); compound 13: catechin (11); compound 14: phlorizin4'-O- $\beta$-D-glucopyranoside (11); compound 15 : $3 \beta, 6 \alpha, 13 \beta$-trihydroxyolean-7-one (11); compound 16: dodecanoic $\operatorname{acid}(11)$.

The structures of these 16 chemical constituents are shown in Fig. 2, and the spectra are described as follows:
Compound 1: the spectrum was reported previously (11). Compound 2: $\mathrm{C}_{32} \mathrm{H}_{50} \mathrm{O}_{5}{ }^{1} \mathrm{H}-\mathrm{NMR}$ (400 MHz, $\mathrm{CDCl}_{3}$-d1) $\delta: 1.14$ $(2 \mathrm{H}, \mathrm{H}-1 \alpha), 2.60(2 \mathrm{H}, \mathrm{ddd}, \mathrm{J}=14.00,3.24,3.24, \mathrm{H}-1 \beta), 1.61(2 \mathrm{H}$, $\mathrm{H}-2), 4.49(1 \mathrm{H}, \mathrm{dd}, \mathrm{J}=12.3,8.0, \mathrm{H}-3 \alpha), 1.54(1 \mathrm{H}, \mathrm{H}-5), 4.92$ $(1 \mathrm{H}, \mathrm{d}, \mathrm{J}=12.03, \mathrm{H}-6 \beta), 0.83$ (1H, H-9), 1.57 (2H, H-11), 1.21 (2H, H-12), 1.00 (2H, H-15 $\alpha$ ), 2.11 (2H, ddd, J=13.74, 13.6, 4.2, H-15ß), 1.82 (2H, ddd, J=13.48, 12.70, 3.97, H-16 $\alpha$ ), 1.19 $(2 \mathrm{H}, \mathrm{H}-16 \beta), 1.51$ (1H, H-18), $1.98(2 \mathrm{H}, \mathrm{dd}, \mathrm{J}=12.74, \mathrm{H}-19 \alpha)$, 1.25 (2H, H-19ß), 1.47 (2H, H-21a), 1.33 (2H, H-21b), 1.39 $(2 \mathrm{H}, \mathrm{H}-22 \mathrm{a}), 1.10(2 \mathrm{H}, \mathrm{H}-22 \mathrm{~b}), 0.87$ (3H, s, H-23), 0.90 (3H, s, H-24), 1.19 (3H, s, H-25), 1.37 (3H, s, H-26), 0.92 (3H, s, H-27), 1.23 (3H, s, H-28), 0.95 (3H, s, H-29), 0.89 (3H, s, H-30), 2.04 $(3 \mathrm{H}, \mathrm{H}-2 \mathrm{\prime}){ }^{13} \mathrm{C}-\mathrm{NMR}\left(100 \mathrm{MHz}, \mathrm{CDCl}_{3}-\mathrm{d} 1\right)$ 8: 39.9 (C-1), 23.8 (C-2), 80.5 (C-3), 39.3 (C-4), 56.7 (C-5), 72.2 (C-6), 211.2 (C-7), 43.3 (C-8), 55.3 (C-9), 38.2 (C-10), 17.5 (C-11), 33.9 (C-12), 82.3 (C-13), 45.0 (C-14), 22.5 (C-15), 29.7 (C-16), 33.5 (C-17), 49.1 (C-18), 38.5 (C-19), 31.3 (C-20), 34.0 (C-21), 39.0 (C-22), 


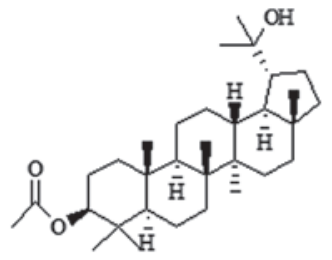

1

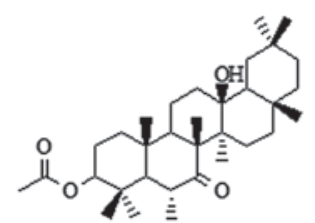

2

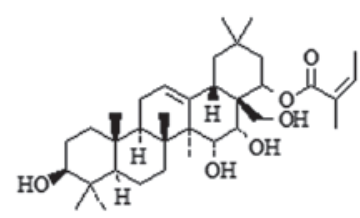

3<smiles>CC(=O)/C=C/[C@H]1C(C)=C[C@@H](O)CC1(C)C</smiles>

4

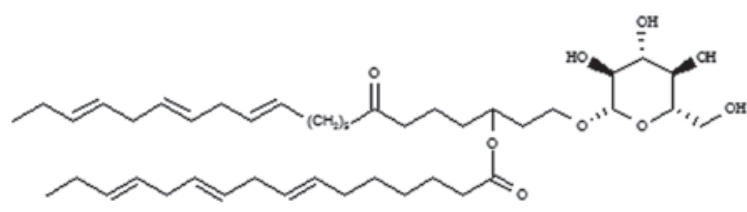

5

7

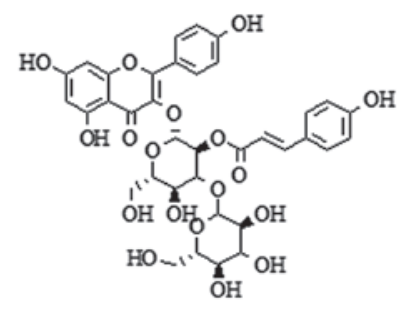

8

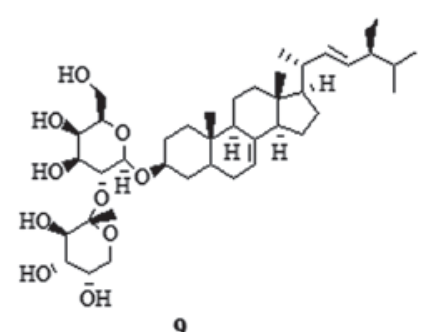

9

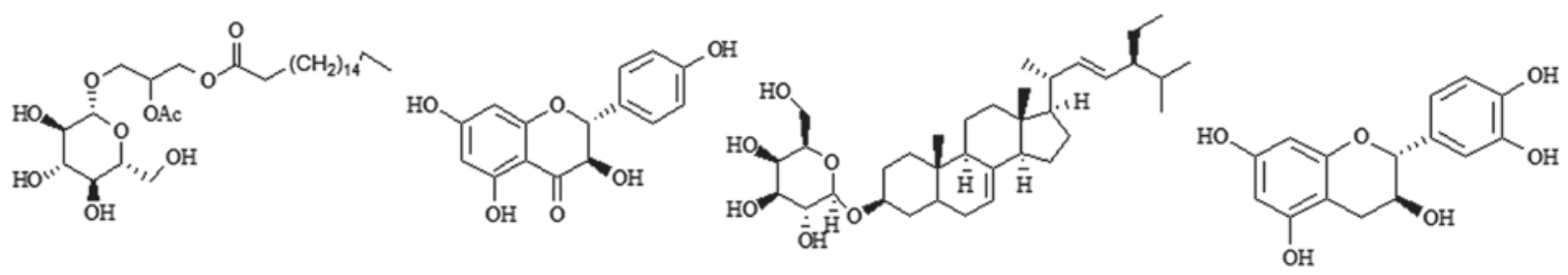

11

12

13<smiles>O=C(CCc1ccc(O)cc1)c1c(O)cc(O[C@@H]2O[C@H](CO)[C@@H](O)[C@H](O)[C@H]2O)cc1O</smiles>

14

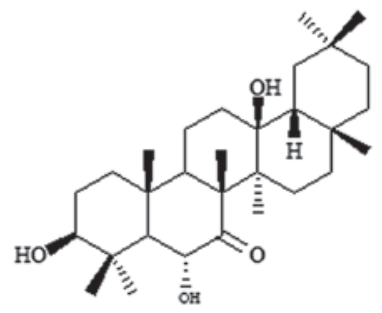

15<smiles>CCCCCCCCCCCC(=O)O</smiles>

16

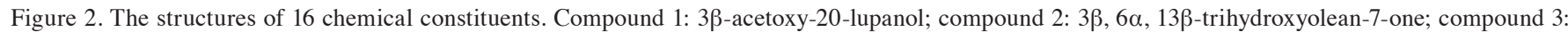
A1-barrigenol22a-angelate; compound4:(3R,6R,7E)-3-hydroxy-4,7-megastigmadien-9-one; $\psi$ ompound 5: $\beta$-D-glucopyranoside,3-[(1-oxo-9,12,15-octadecadienyl)oxy]-2-[(1-oxo-9,12,15-octadecatrienyl)oxy]; compound 6: $\beta$-D-glucopyranoside,2-[[(9Z,12Z, 15Z)-1-oxo-9,12,15-octadecatrien-1-yl]oxy]-3-[(1-oxooctyl) oxy]propyl; compound 7: $\beta$-D-glucopyranoside, 3-[(1-oxo-9,12-octadecadienyl)oxy]-2-[(1-oxo-9,12,15-octadecatrienyl)oxy]propyl; compound 8: kaempferol; compound 9: stigmasta-7,22-diene-3-O -[ $\alpha$-L-arabinopyranosyl $(1 \rightarrow 2)]-\beta-D$-galactopyranoside; compound 10: $\beta$-D- galactopyranoside, $(2 \mathrm{~S})-2$-(acetyloxy)3-[[(9Z)-1-oxo-9-octadecen-1-yl]oxy]propyl; compound 11: aromadendrin; compound 12: $\alpha$-spinasteryl- $\beta$-D-glucopyranoside; compound 13: catechin;

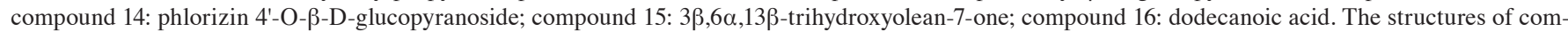
pound $1,4,8,9,11,12,13,14,15$ and 16 were reported in our previous study (11).

28.1 (C-23), 16.4 (C-24), 16.0 (C-25), 20.5 (C-26), 18.4 (C-27), 31.3 (C-28), 31.8 (C-29), $\left.25.0(\mathrm{C}-30), 171.0\left(\mathrm{C}-1^{\prime}\right), 21.3(\mathrm{C}-2)^{\prime}\right)$. Compound 3: $\mathrm{C}_{35} \mathrm{H}_{52} \mathrm{O}_{6}{ }^{1} \mathrm{H}-\mathrm{NMR}(600 \mathrm{MHz}, \mathrm{MeOH}-\mathrm{d} 4)$ $\delta: 3.17(1 \mathrm{H}, \mathrm{dd}, \mathrm{J}=4.2,11.4, \mathrm{H}-3), 5.26(1 \mathrm{H}, \mathrm{t}, \mathrm{J}=3.6, \mathrm{H}-12), 3.79$ $(1 \mathrm{H}, \mathrm{d}, \mathrm{J}=10.2, \mathrm{H}-15), 3.92(1 \mathrm{H}, \mathrm{d}, \mathrm{J}=4.2, \mathrm{H}-16), 2.54(1 \mathrm{H}, \mathrm{dd}$, $\mathrm{J}=4.2,14.4, \mathrm{H}-18), 5.45$ (1H, dd, J=6.0, 12.0, H-22), 0.98 (3H, s,
H-23), 0.78 (3H, s, H-24), 0.95 (3H, s, H-25), 1.02 (3H, s, H-26), 1.40 (3H, s, H-27), 3.09, 3.22 (2H, d, J=10.8, H-28), 0.90 (3H, s, H-29), 1.04 (3H, s, H-30), 6.03 (1H, dq, J=1.2, 7.2, H-3'), 1.99 $\left(3 \mathrm{H}, \mathrm{dd}, \mathrm{J}=1.8,7.2, \mathrm{H}-4^{\prime}\right), 1.90$ (3H, br t, J=1.8, H-5') ${ }^{13} \mathrm{C}-\mathrm{NMR}$ (150 MHz, MeOH-d4) d: 39.8 (C-1), 27.9 (C-2), 79.7 (C-3), 38.2 (C-4), 56.6 (C-5), 19.7 (C-6), 37.2 (C-7), 41.9 (C-8), 48.2 

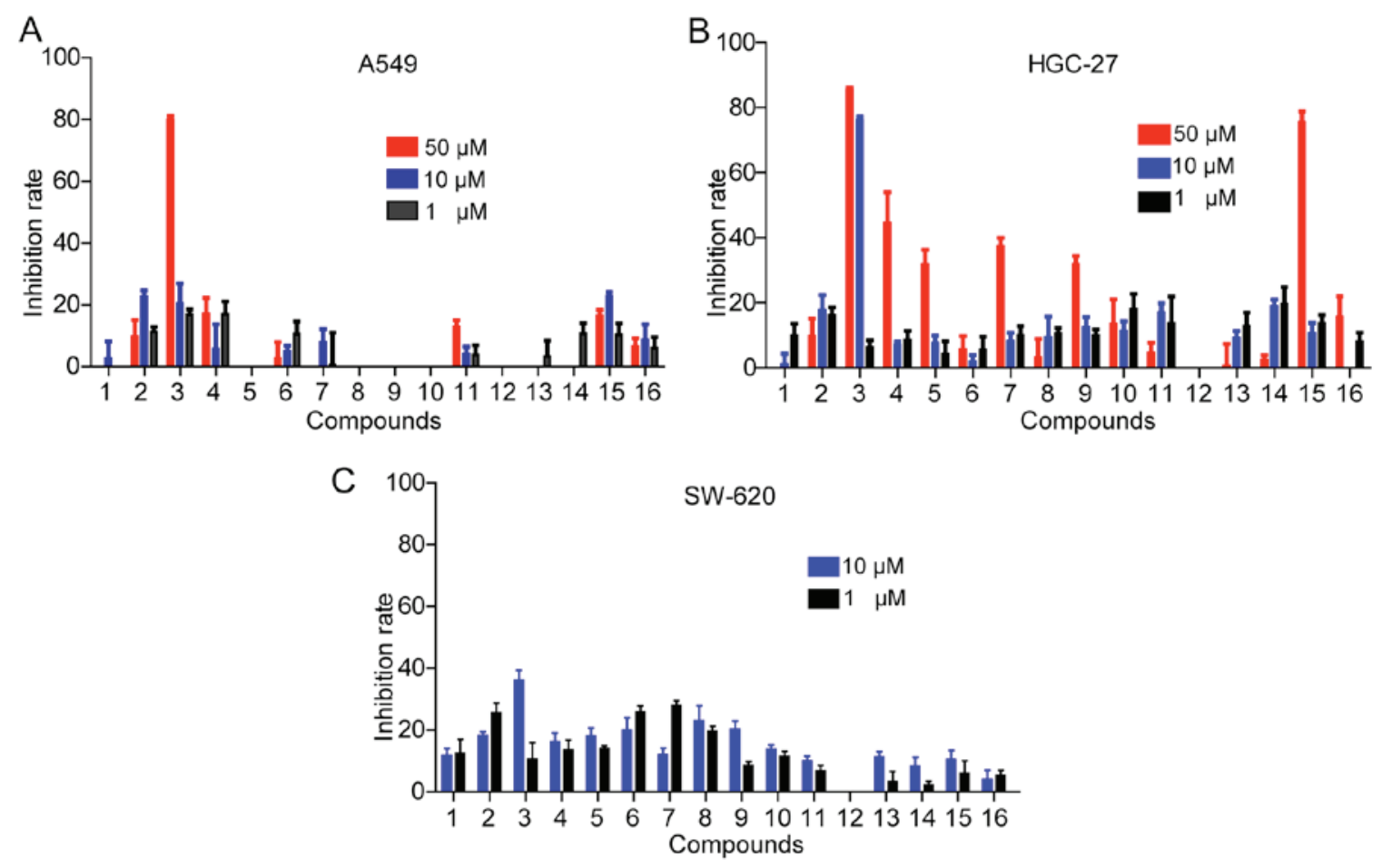

Figure 3. Antitumor activity screening of the chemical constituents. (A) A549 and (B) HGC-27 cells were treated with the 16 chemical constituents at concentrations of 1,10 and $50 \mu \mathrm{M}$ for $72 \mathrm{~h}$. (C) SW-620 cells were treated with the 16 chemical constituents at concentrations of 1 and $10 \mu \mathrm{M}$ for $72 \mathrm{~h}$. The effect of 16 chemical constituents on cell growth was examined by MTT assay. Each experiment was repeated at least three times. Bars represent the SEM.

(C-9), 33.6 (C-10), 24.7 (C-11), 123.4 (C-12), 144.5 (C-13), 45.7 (C-14), 68.5 (C-15), 75.4 (C-16), 41.9 (C-17), 42.9 (C-18), 47.6 (C-19), 33.6 (C-20) 42.3 (C-21), 73.3 (C-22), 28.7 (C-23), 16.2 (C-24), 15.9 (C-25), 17.8 (C-26), 20.9 (C-27), 63.8 (C-28), 32.4 (C-29), 25.1 (C-30), 169.5 (C-1'), 130.0 (C-2'), 138.1 (C-3'), 16.3 (C-4'), 21.1 (C-5'). Compound 4: the spectrum was reported previously (11). Compound 5: $\mathrm{C}_{41} \mathrm{H}_{66} \mathrm{O}_{10}{ }^{1} \mathrm{H}-\mathrm{NMR}(600 \mathrm{MHz}$, MeOH-d4) ס: 3.97 (2H, dd, J=5.410.8, H-1), 4.22 (2H, d, J=7.2, H-3) ${ }^{13} \mathrm{C}-\mathrm{NMR}(150 \mathrm{MHz}, \mathrm{MeOH}-\mathrm{d} 4)$ ): 68.7 (C-1), 70.2 (C-2), 64.0 (C-3), 105.4 (C-1'), 72.4 (C-2'), 74.9 (C-3'), 71.8 (C-4'), 76.8 (C-5'), 62.5 (C-6'), 175.0 (C-1"), 174.7 (C-1"'), 23.6-35.1 (C-2"-C-6", C-9", C-12", C-15", C-2"'-C-6"', C-9"', C-12'", C-15"'), 129.1-133.8 (C-7"-C-8", C-10"-C-11", C-13"-C-14", C-7"'-C-8"', C-10"'-C-11"', C-13'"-C-14"'), 14.5 (C-16"), 14.5 (C-16"'). Compound 6: $\mathrm{C}_{35} \mathrm{H}_{60} \mathrm{O}_{10}{ }^{1} \mathrm{H}-\mathrm{NMR}$ (600 MHz, MeOH-d4) $\delta: 4.42(1 \mathrm{H}, \mathrm{dd}, \mathrm{J}=3,12, \mathrm{H}-6 \mathrm{\prime}), 5.19(1 \mathrm{H}, \mathrm{m}, \mathrm{C}=\mathrm{CH}){ }^{13} \mathrm{C}-\mathrm{NMR}$ (150 MHz, MeOH-d4) d: 68.7 (C-1), 71.8 (C-2), 64.0 (C-3), 105.4 (C-1'), 72.4 (C-2'), 74.9 (C-3'), 70.2 (C-4'), 76.8 (C-5'), 62.5 (C-6'), 175.1 (C-1"), 174.8 (C-1"'), 129.0-133.8 (C-9"'-C-10"', C-12'"-C-13'"', C-15"'-C-16"'), 26.0-35.1 (C-2"'-C-8", C-11"', C-14"', C-17"'), 14.0 (C-8"), 14.4 (C-18"). Compound 7: $\mathrm{C}_{45} \mathrm{H}_{76} \mathrm{O}_{10}$ ${ }^{1} \mathrm{H}-\mathrm{NMR}(600 \mathrm{MHz}, \mathrm{MeOH}-\mathrm{d} 4)$ d: $5.32(1 \mathrm{H}, \mathrm{m}, \mathrm{C}=\mathrm{CH}), 0.06$ (3H, s, H-18", H-18'"), 4.42 (1H, dd, J=3, 12, H-6') ${ }^{13} \mathrm{C}-\mathrm{NMR}$

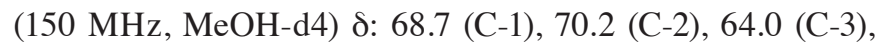
$105.4\left(\mathrm{C}-1^{\prime}\right), 72.4\left(\mathrm{C}-2^{\prime}\right), 74.9\left(\mathrm{C}-3^{\prime}\right), 71.8\left(\mathrm{C}-4^{\prime}\right), 76.8\left(\mathrm{C}-5^{\prime}\right)$, 62.5 (C-6'), 175.0 (C-1"), 174.7 (C-1"'), 128.2 -132.7 (C-9"-C-10", C-12"-C-13", C-15"'-C-16"', C-9"'-C-10"', C-12'"-C-13"'), 21.5-35.1 (C-2"-C-8", C-11", C-14"-C-17", C-2"'-C-8'", C-11"', $\mathrm{C}-16$ "', C-17"'). Compound 8: the spectrum was reported previously (11). Compound 9: the spectrum was reported previously (11). Compound 10: C29H52O10 ${ }^{1} \mathrm{H}-\mathrm{NMR}(600 \mathrm{MHz}$, MeOH-d4) ઈ: 3.97 (2H, dd, J=5.4, 10.8, H-1), 5.25 (1H, m, H-2),
4.21 (2H, dd, J=7.2, 12.0, H-3), 4.17 (1H, d, J=7.8, H-1'), 3.45 (1H, H-2'), 3.40 (1H, dd, J=3.6, 9.6,H-3'), 3.76 (1H, d, J=3.6, H-4'), 3.44 (1H, m, H-5'), 3.67 (2H, H-6') ${ }^{13} \mathrm{C}-\mathrm{NMR}(150 \mathrm{MHz}$, MeOH-d4) d: 68.7 (C-1), 71.8 (C-2), 64.0 (C-3), 105.4 (C-1'), 72.4 (C-2'), 74.9 (C-3'), 70.2 (C-4'), 76.8 (C-5') 62.5 (C-6'), 175.0 (C-1"), 174.7 (C-1"'), 26.0-35.1 (C-2"-C-8", C-11"-C-17"), 129.2 (C-9"), 128.9 (C-10"), 14.0 (C-18"), 14.0 (C-2"'). Compound 11: the spectrum was reported previously (11). Compound 12: the spectrum was reported previously (11). Compound 13: the spectrum was reported previously (11). Compound 14: the spectrum was reported previously (11). Compound 15: the spectrum was reported previously (11). Compound 16: the spectrum was reported previously (11).

In conclusion, excluding compound 11 and compound 1, other 14 chemical constituents were first discovered in this plant by our group. In this study, 6 phytochemicals (compound 2, 3, 5, 6, 7 and 10) were reported for the first time in this plant, whereas other 8 phytochemicals were first reported in this plant in our previously published study (11). The preliminary screening of the extractive fractions for antitumor activity showed that the extracts of C. nitidissima could significantly inhibit cancer cell proliferation by MTT assays and mouse sarcoma 180 subcutaneous graft tumor model in our previous study (18). However, the antitumor activity of the 16 specific chemical constituents need to be evaluated.

The antitumor activity screening of 16 chemical constituents. Lung cancer, gastric cancer, breast cancer and colon cancer are the most common malignant tumors worldwide, and especially in China. Therefore, the 16 chemical constituents from C. nitidissima were screened for antitumor activity on 3 cancer cell lines via MTT assays. As shown in Fig. 3A and B, several natural medicines exhibited significant antitumor effects on 

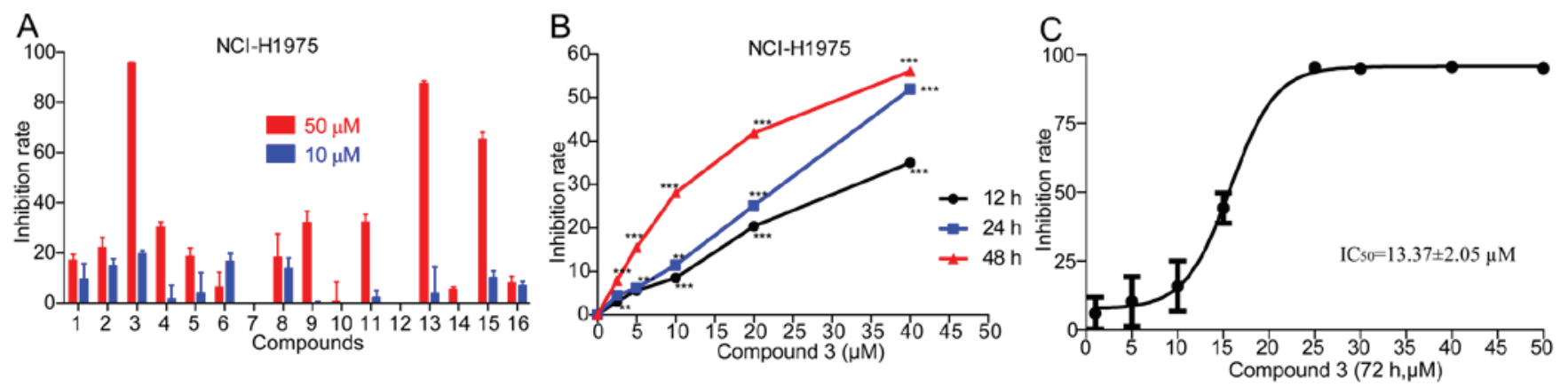

Figure 4. The antitumor activity of compound 3 on EGFR-T790M resistance NSCLC cells. (A) NCI-H1975 cells were treated with the 16 chemical constituents at concentrations of 10 and $50 \mu \mathrm{M}$ for $72 \mathrm{~h}$. (B) NCI-H1975 cells were treated with various concentrations of compound 3 for 12, 24 and $48 \mathrm{~h}$. (C) NCI-H1975 cells were treated with compound 3 at concentrations ranging from 1 to $50 \mu \mathrm{M}$ for $48 \mathrm{~h}$ and the value of $\mathrm{IC}_{50}$ was calculated. The effect of compound 3 on cell growth was examined by MTT assay. Each experiment was repeated at least three times. Bars represent the SEM. Values significantly different from that of the control group are denoted with an asterisk $(\mathrm{P}<0.05)$.
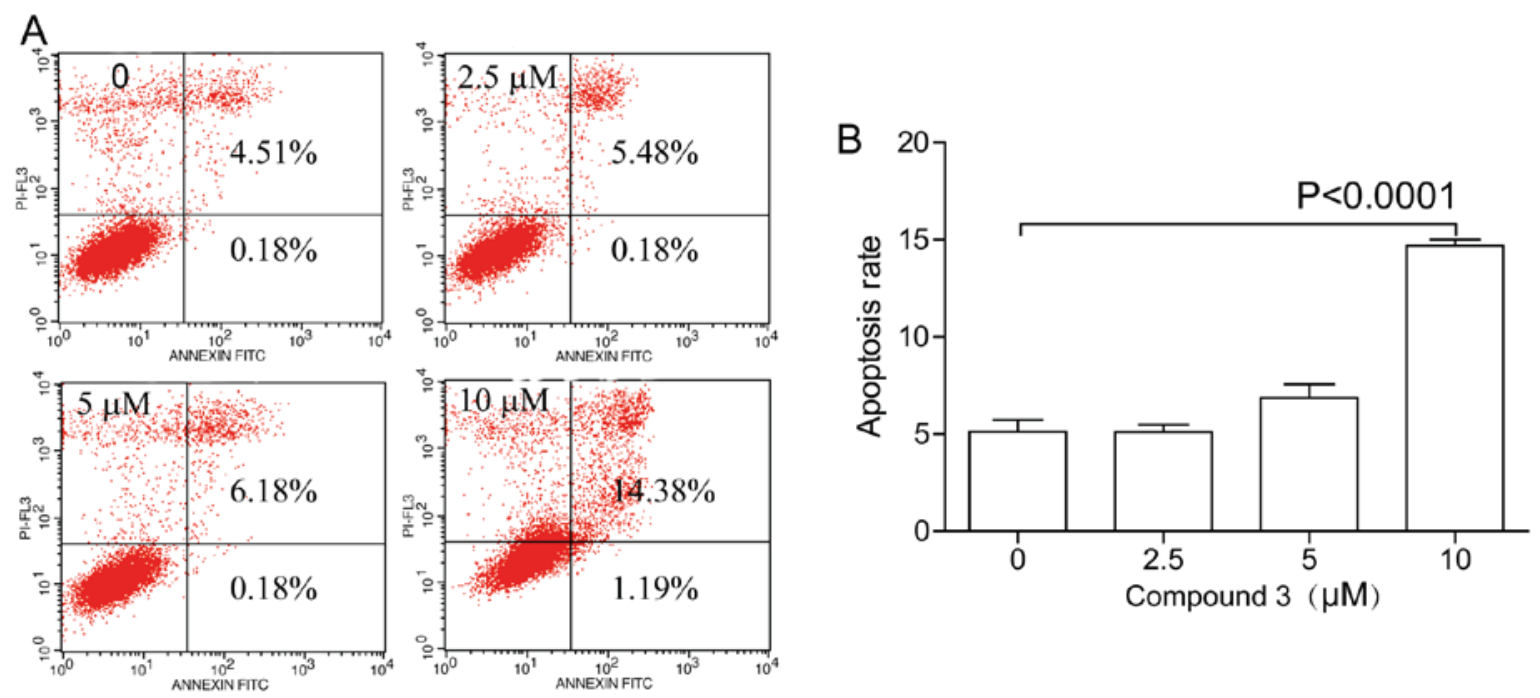

Figure 5. Compound 3 induces apoptosis of the NCI-H1975 cell line. (A) NCI-H1975 cells were treated with compound 3 at concentrations of $2.5,5$ and $10 \mu \mathrm{M}$ for $48 \mathrm{~h}$. Cell apoptosis percentages were determined by flow cytometry with Annexin V/PI double staining (means \pm SD). (B) The degree of apoptotic cell death was quantified for each condition. The experiment was repeated at least three times.

A549 and HGC-27 at a high concentration $(50 \mu \mathrm{M})$. However, only compound 3 even had evident antitumor effects at $10 \mu \mathrm{M}$. Furthermore, the 16 chemical constituents exhibited little effect on SW620 (Fig. 3C). Compared to the other chemical constituents, compound 3 showed superior antitumor effects. Interestingly, to our knowledge, this is the first study that compound 3 inhibited cancer cells. In brief, compound 2, 3 and 15 exhibited more significant antitumor effect than others, showing potential for antitumor drug development.

The antitumor activity of compound 3 on EGFR-T790M resistant NSCLC cell line NCI-H1975. Our group has focused on EGFR and EGFR inhibitors for a long time (19). The recognized EGFRmutant lung cancer cell line, NCI-H1975 has a point mutation for T790M in exon 20, which confers resistance to first-generation EGFR TKIs such as gefitinib and erlotinib (20). As the screening data in Fig. 4, only 3 natural medicines exhibited significant antitumor effect on the NCI-H1975 cell line (Fig. 4A). Obviously, compound 3 had the most prominent antitumor effect in the 16 natural medicines, based on the screening data of 4 common malignant cancer cell lines. Furthermore, compound 3 inhibited the proliferation of NCI-H1975 in a dose and time-dependent manner (Fig. 4B)with an the $\mathrm{IC}_{50}$ of $13.37 \pm 2.05 \mu \mathrm{M}$ at $48 \mathrm{~h}$ treatment (Fig. 4C). Therefore, to our knowledge, this is the first study showing that compound 3 may help solve the problem of drug resistance to first-generation EGFR TKIs.

Compound 3 induces apoptosis of the NCI-H1975 cell line. The antitumor effect of compound 3 was confirmed in above results, but the mechanisms relating to the antitumor activity remained unknown. Apoptosis is one of the most common mechanisms of natural medicines $(21,22)$. The Annexin V/PI double staining showed significant apoptosis effects of compound 3 on NCI-H1975 at $10 \mu \mathrm{M}$ (Fig. 5).

Furthermore, the marker proteins of apoptosis effect such as cleaved caspase-3, caspase- 9 and cleaved PARP, were upregulated by compound 3 (Fig. 6). The relevant apoptosis pathways included mitochondrial mediated apoptosis and death receptor mediated apoptosis. The expression of Bax was upregulated, but the expression of Bcl-2 was downregulated (Fig. 6), suggesting apoptosis may be via mitochondrial mediated apoptosis pathway. 
A

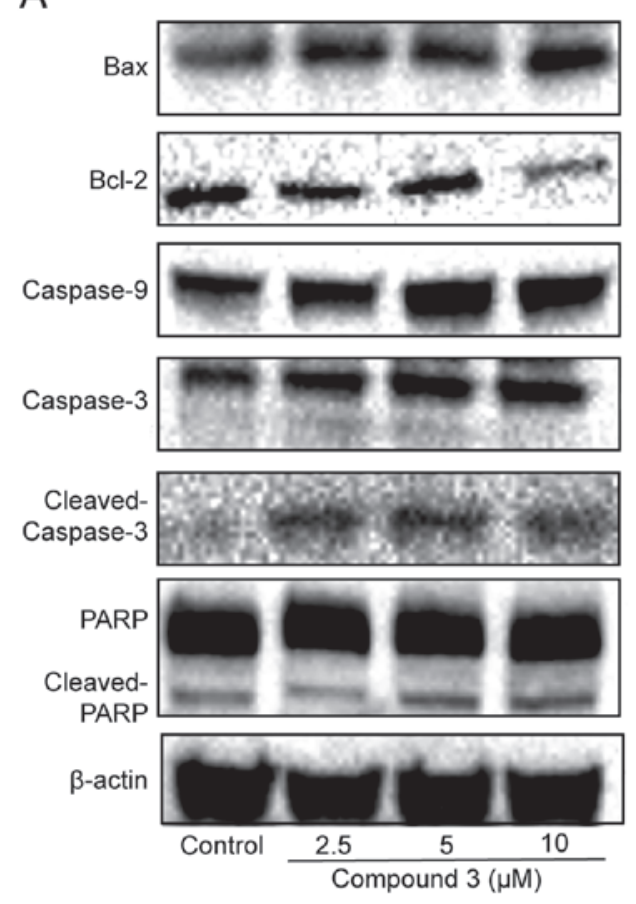

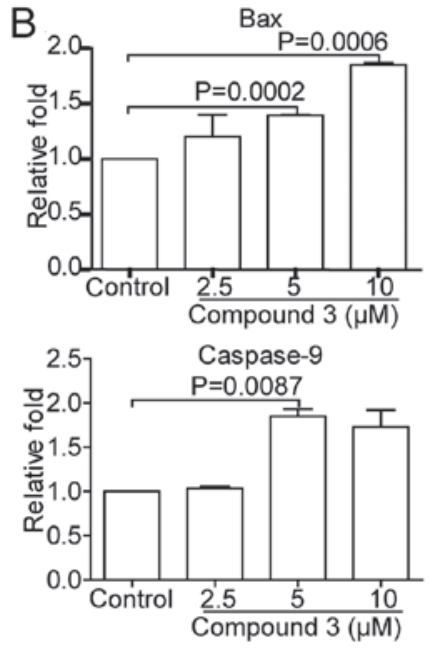

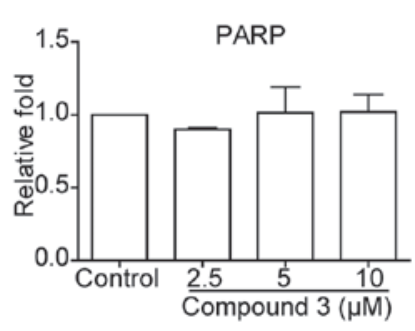

$\mathrm{Bcl}-2$
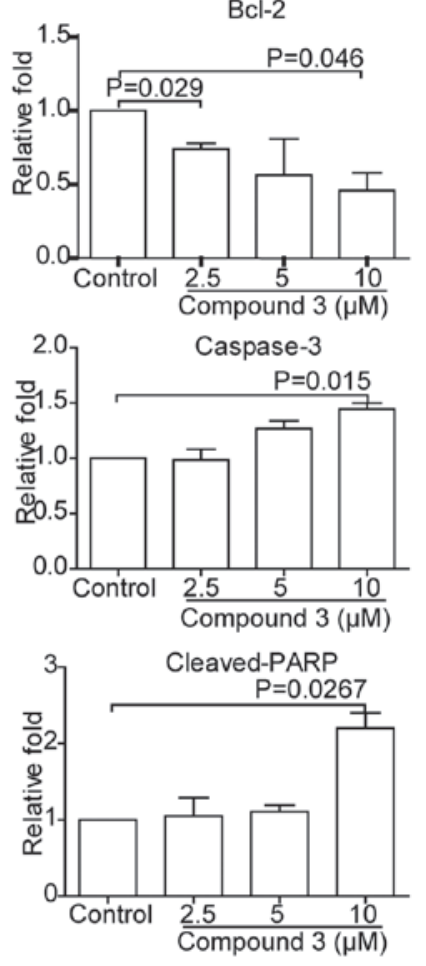

Figure 6. The apoptosis effect on NCI-H1975 induced by compound 3 via the mitochondrial mediated apoptosis pathway. (A) NCI-H1975 cells were treated with compound 3 at concentrations of $2.5,5$ and $10 \mu \mathrm{M}$ for $48 \mathrm{~h}$. Cells were lysed for the detection of the expression of Bax, Bcl-2, caspase-9, caspase-3, cleaved caspase-3, PARP, cleaved PARP and $\beta$-actin by western blot analysis. (B) Relative protein levels compared to the control group are shown as mean \pm SD. The experiment was repeated at least three times.

\section{Discussion}

The drug development based on natural medicine is considered to be a more targeted approach (23) than random screening. An increasing number of researchers all over the world are focusing on natural medicine to find new antitumor drugs $(24,25)$. In this study, 16 chemical constituents were isolated from the leaves of $C$. nitidissima, and 6 compounds were discovered in this plant for the first time. Meanwhile, an oleanane-type triterpene, compound 3, exhibited the most potential antitumor effects, based on a mass of drug screening studies. To our knowledge, this is the first study that compound 3 inhibited cancer cells, and compound 3 could inhibit the EGFR-mutant lung cancer cell line NCI-H1975 via apoptosis effect. Based on these data, compound 3 showed potential for antitumor drug development.

Several previous studies $(9,26)$ have suggested that the crude extracts of $C$. nitidissima could inhibit cancer growth, whereas our study also showed the prevention effects of crude extracts on carcinogenesis. However, the pharmacodynamics of the chemical constituents derived from C. nitidissima need to be explored. Until now, only a few chemical constituents have been isolated and identified from $C$. nitidissima (11). Therefore, 6 compounds among the 16 chemical constituents are first reported in this plant. Furthermore, based on extensive drug screening, compound 3 was found to be a potential antitumor drug. Interestingly, to our knowledge, this is the first study of compound 3 demonstrating an antitumor effect. Consequently, these data provide the scientific basis for antitumor activity of $C$. nitidissima.

Compound 3 is an oleanane-type triterpene which is widely used in traditional Chinese medicine (TCM), and is the most common type of terpene (27). Common triterpenoids can be divided into oleanane type, dammarane type, ursane type, lupane type and friedelane type. Triterpene compounds have many beneficial physiological and pharmacological functions (27), including antitumor, anti-inflammatory, antiviral, and antibacterial activities. Therefore, triterpene components can be considered as potential therapeutic strategy for the prevention and treatment of tumors in the future (28).

Chemotherapy is the preferred and the most common treatment for patients in clinical practice (2). Although, the world famous pharmaceutical companies have been committed to antitumor drugs development, there is a lack of effective antitumor drugs. Because some patients easily acquire resistance to many new drugs after a period of treatment. For example the mutation of T790M confers resistance to first-generation EGFR TKIs $(20,29)$. Our group has been focused on natural medicines for antitumor effect. And, we have discovered some effective antitumor drugs from traditional Chinese Medicine $(19,30)$. It is believed that the drug development based on natural medicine is a more targeted approach.

The antitumor effects of compound 3 on lung cancer cells via apoptosis were significant, in vitro. However, the detailed regulation mechanisms may need to be further explored. Similar to many studies on natural medicine (31), the antitumor effects should be confirmed via orthotopic tumor models, in vivo.

On the basis of these findings, compound 3 showed the potential to be developed as an antitumor drug, and provided a scientific basis for the antitumor activity of $C$. nitidissima. The study based on natural medicine is a targeted mode for new drug research and development. 


\section{Acknowledgements}

The authors would like to thank the Jiangsu Key Laboratory of Drug Screening and Jiangsu Center for Pharmacodynamics Research and Evaluation for providing the facilities to carry out this research.

\section{Funding}

This study was funded by the National High-tech Research and Development Projects (863) (no. 2014AA022208), the National Natural Science Foundation of China (no. 81573456) and the National Undergraduate Innovation Program in China Pharmaceutical University (no. 2016-114).

\section{Availability of data and materials}

The datasets used and/or analyzed during the current study are available from the corresponding author on reasonable request.

\section{Authors' contributions}

SY and LS defined the research subject and its aims, conceived and designed the experiments. XH, HD, RY, JQ and YH conducted the experiments. SF, YW, SL, ZL and AJ analyzed the data. XH and HD wrote the paper.

\section{Ethics approval and consent to participate}

Not applicable.

\section{Consent for publication}

Not applicable.

\section{Competing interests}

The authors declare that they have no competing interests.

\section{References}

1. Chen W, Zheng R, Zhang S, Zhao P, Zeng H, Zou X and He J: Annual report on status of cancer in China, 2010. Chin J Cancer Res 26: 48-58, 2014.

2. Moth E, McLachlan SA, Veillard AS, Muljadi N, Hudson M, Stockler MR and Blinman P: Patients' preferred and perceived roles in making decisions about adjuvant chemotherapy for nonsmall-cell lung cancer. Lung Cancer 95: 8-14, 2016.

3. Tricker EM, Xu CX, Wong KK and Janne PA: Efficacy of cetuximab and mutant selective EGFR inhibitor WZ4002 in EGFR T790M and non-T790M models of erlotinib resistant non-small cell lung cancer. Cancer Res (Suppl 15) 75: 2813, 2015

4. Konkimalla VB and Efferth T: Anti-cancer natural product library from traditional Chinese medicine. Comb Chem High Throughput Screen 11: 7-15, 2008.

5. Du H, Huang Y, Hou X, Yu X, Lin S, Wei X, Li R, Khan GJ, Yuan S and Sun L: DT-13 inhibits cancer cell migration by regulating NMIIA indirectly in the tumor microenvironment. Oncol Rep 36: 721-728, 2016.

6. Li L and Leung PS: Use of herbal medicines and natural products: An alternative approach to overcoming the apoptotic resistance of pancreatic cancer. Int J Biochem Cell Biol 53: 224-236, 2014.

7. Xu X, Chen D, Ye B, Zhong F and Chen G: Curcumin induces apoptosis of non-small cell lung cancer cells through a calcium signaling pathway. Int J Mol Med 35: 1610-1616, 2015.
8. Wang W, Liu H, Wang Z, Qi J, Yuan S, Zhang W, Chen H, Finley JW, Gu L and Jia AQ: Phytochemicals from Camellia nitidissima Chi inhibited the formation of advanced glycation endproducts by scavenging methylglyoxal. Food Chem 205: 204-211, 2016.

9. Dai L, Li JL, Liang XQ, Li L, Feng Y, Liu HZ, Wei WE, Ning SF and Zhang LT: Flowers of Camellia nitidissima cause growth inhibition, cell-cycle dysregulation and apoptosis in a human esophageal squamous cell carcinoma cell line. Mol Med Rep 14: $1117-1122,2016$.

10. Oku H, Ogawa Y, Iwaoka E, Yamaguchi Y, Kagota S, Kazumasa S, Kunitomo $M$ and Ishiguro K: Preventive effects of the extract of kinka-cha, a folk tea, on a rat model of metabolic syndrome. J Nat Med 65: 610-616, 2011.

11. Qi J, Shi RF, Yu JM, Li Y, Yuan S, Yang J, Hu J and Jia A: Chemical constituents from leaves of Camellia nitidissima and their potential cytotoxicity on SGC7901 cells. Chin Herb Med 8: 80-84, 2016.

12. Ling TJ, Wan XC, Ling WW, Zhang ZZ, Xia T, Li DX and Hou RY: New triterpenoids and other constituents from a special microbial-fermented tea-Fuzhuan brick tea. J Agric Food Chem 58: 4945-4950, 2010.

13. Ren Y, VanSchoiack A, Chai HB, Goetz M and Kinghorn AD: Cytotoxic Barrigenol-like triterpenoids from an extract of Cyrilla racemiflora housed in a repository. J Nat Prod 78: 2440-2446, 2015.

14. Bruns N, Collisi W, Bernecker S, Stadler M, Richter C, Schwalbe $\mathrm{H}$ and Kalesse M: Spirangien derivatives from the myxobacterium Sorangium cellulosum: Isolation, structure elucidation, and biological activity. Eur J Org Chem 2015: 847-857, 2015.

15. Cateni F, Bonivento P, Procida G, Zacchigna M, Scialino G and Banfi E: Chemoenzymatic synthesis and in vitro studies on the hydrolysis of antimicrobial monoglycosyl diglycerides by pancreatic lipase. Bioorg Med Chem Lett 17: 1971-1978, 2007.

16. Abrous-Belbachir $\mathrm{O}$, De Paepe R, Trémolières $\mathrm{A}$, Mathieu $\mathrm{C}$, Ad F and Benhassaine-Kesri G: Evidence that norflurazon affects chloroplast lipid unsaturation in soybean leaves (Glycine max L.). J Agric Food Chem 57: 11434-11440, 2009.

17. Janwitayanuchit W, Suwanborirux K, Patarapanich C, Pummangura S, Lipipun V and Vilaivan T: Synthesis and anti-herpes simplex viral activity of monoglycosyl diglycerides. Phytochemistry 64: 1253-1264, 2003.

18. Huang Y, Hou XY, Guo H, Lin SS, Yuan ST and Sun L: Anti-tumor effect of Camellia nitidissima Chi extracts in vitro and in vivo. Asia-Pac Tradit Med Chin 12: 8-11, 2016.

19. Yu XW, Lin S, Du HZ, Zhao RP, Feng SY, Yu BY, Zhang LY, Li RM, Qian CM, Luo XJ, et al: Synergistic combination of DT-13 and topotecan inhibits human gastric cancer via myosin IIA-induced endocytosis of EGF receptor in vitro and in vivo. Oncotarget 7: 32990-33003, 2016.

20. Sakuma Y, Yamazaki Y, Nakamura Y, Yoshihara M, Matsukuma S, Nakayama H, Yokose T, Kameda Y, Koizume S and Miyagi Y: WZ4002, a third-generation EGFR inhibitor, can overcome anoikis resistance in EGFR-mutant lung adenocarcinomas more efficiently than Src inhibitors. Lab Invest 92: 371-383, 2012.

21. Cao W, Liu Y, Zhang R, Zhang B, Wang T, Zhu X, Mei L, Chen H, Zhang H, Ming P, et al: Homoharringtonine induces apoptosis and inhibits STAT3 via IL-6/JAK1/STAT3 signal pathway in Gefitinib-resistant lung cancer cells. Sci Rep 5: 8477, 2015.

22. Wang W, Luo J, Liang Y and Li X: Echinacoside suppresses pancreatic adenocarcinoma cell growth by inducing apoptosis via the mitogen-activated protein kinase pathway. Mol Med Rep 13: 2613-2618, 2016.

23. Wang CY, Bai XY and Wang CH: Traditional Chinese medicine: A treasured natural resource of anticancer drug research and development. Am J Chin Med 42: 543-559, 2014.

24. Chan SM and Ye JM: Strategies for the discovery and development of anti-diabetic drugs from the natural products of traditional medicines. J Pharm Pharm Sci 16: 207-216, 2013.

25. Luo X, Yu X, Liu S, Deng Q, Liu X, Peng S, Li H, Liu J and Cao Y: The role of targeting kinase activity by natural products in cancer chemoprevention and chemotherapy (Review). Oncol Rep 34: 547-554, 2015.

26. Song LX, Wang XS, Zheng XQ and Huang DJ: Polyphenolic antioxidant profiles of yellow camellia. Food Chem 129: 351-357, 2011. 
27. Zhang W, Men X and Lei P: Review on anti-tumor effect of triterpene acid compounds. J Cancer Res Ther 10 (Suppl 1): 14-19, 2014.

28. Yang H, Chen D, Cui QC, Yuan X and Dou QP: Celastrol, a triterpene extracted from the Chinese 'Thunder of God Vine' is a potent proteasome inhibitor and suppresses human prostate cancer growth in nude mice. Cancer Res 66: 4758-4765, 2006.

29. Ofuji K, Tada Y, Yoshikawa T, Shimomura M, Yoshimura M, Saito K, Nakamoto $\mathrm{Y}$ and Nakatsura T: A peptide antigen derived from EGFR T790M is immunogenic in non small cell lung cancer. Int J Oncol 46: 497-504, 2015.

30. Fan W, Sun L, Zhou JQ, Zhang C, Qin S, Tang Y, Liu Y, Lin SS and Yuan ST: Marsdenia tenacissima extract induces G0/G1 cell cycle arrest in human esophageal carcinoma cells by inhibiting mitogen-activated protein kinase (MAPK) signaling pathway. Chin J Nat Med 13: 428-437, 2015.
31. Bai Y, Chen B, Hong W, Liang Y, Zhou M and Zhou L: Sedum sarmentosum Bunge extract induces apoptosis and inhibits proliferation in pancreatic cancer cells via the hedgehog signaling pathway. Oncol Rep 35: 2775-2784, 2016.

(i) (5) This work is licensed under a Creative Commons Attribution-NonCommercial-NoDerivatives 4.0 International (CC BY-NC-ND 4.0) License. 